\title{
The Re-Discovering of Old Molecules to face the Antibiotic Crisis
}

\section{Domenico Schillaci1* and Stella Cascioferro ${ }^{1,2}$}

${ }^{1}$ Department of Biological Chemical and Pharmaceutical Science and Technology, Università degli Studi di Palermo, Italy

${ }^{2}$ IEMEST - Istituto Euromediterraneo di Scienza e Tecnologia, Palermo, Italy

\section{Editorial}

Drug-resistant bacteria are responsible for 5,000 deaths a year in the UK, 25,000 deaths a year in Europe and it is estimated that at least two million people in the United States are infected each year and 23,000 of those die from pathogens that are not susceptible to the treatment by any of current antibiotics [13]. Antibiotic resistance of common pathogenic microorganisms is a topic of great concern and it has finally attracted the attention of mass-media and of some global leaders. For example, President Obama, answering the question "Is antibiotic resistance a threat to global security?" has replied "Effective antibiotics are vital to our national security... They are, quite simply, essential to the health of our people and people everywhere. So we should do everything in our power to ensure that antibiotics remain effective. These vital drugs have saved countless lives over the past century. It is up to us to make sure they keep saving lives for years to come" [14]. Prime Minister David Cameron has recently said "The world could soon be cast back into the dark ages of medicine unless action is taken to tackle the growing threat of resistance to antibiotics" [15].

A public health agency as Center for Desease Control and Prevention (CDC) has established the following objectives, to be achieved by 2020 , to combat antibiotic-resistant bacteria: reduce by $50 \%$ the incidence of overall Clostridium difficile infection compared to estimates from 2011; reduce by $60 \%$ carbapenem-resistant Enterobacteriaceae infections acquired during hospitalization compared to estimates; maintain the prevalence of ceftriaxone-resistant Neisseria gonorrhoeae below 2\% compared to estimates from 2013; reduce by $35 \%$ multidrug-resistant Pseudomonas spp. infections acquired during hospitalization compared to estimates from 2011; reduce by at least $50 \%$ overall methicillinresistant Staphylococcus aureus (MRSA) bloodstream infections by 2020 as compared to 2011 [16]. Moreover, both in US and UK there are two plans to face the antibiotic crisis, such as respectively the Generating Antibiotic Incentives Now (Gain) and Antibiotic Action, that seek to inform about the need for antibiotic discovery and to stimulate the research and development of new treatments for bacterial infections [1].

In a previous Editorial on JMBT [2], we talked about the research of anti-virulence drugs, drugs whose aim is to strike and disarm pathogens without affecting their growth and therefore with limited selective pressure to promote the rise of antibiotic resistance [3]. That is a very promising field of investigation, but still at its infancy in terms of clinical development. Unfortunately, there is an urgent need to introduce antimicrobial molecules in therapy but the delivering of new antibiotic leads into clinical development is extremely slow and we risk losing the battle against pathogens.

The re-discovering of old antibiotics whose use in therapy has been previously abandoned or of old molecules extremely interesting in terms of antimicrobial activity, but never introduced to market, could be a more rapid way to face the emergence of antibiotic resistance and the lack of new antibiotics.

Efficacy of old antibiotics for the treatment of multidrug resistant (MDR) Gram-negative bacterial infections (polymyxins, fosfomycin, mecillinam, temocillin, and nitrofurantoin); MDR Gram-positive infections (trimethoprim-sulfamethoxazole (TMP/SMX), tetracyclines, chloramphenicol, clindamycin, pristinamycin, rifampicin, and fusidic acid); and MDR tuberculosis (clofazimine, amoxicilline-clavulanate, TMP/SMX, and minocycline); has been recently reviewed by Cassir et al. [4]. The revival of colistin, a polimixin produced by Paenibacillus polymyxa subspecies colistinus, is a significative example of the reintroduction in the treatment of infectious diseases of an old antibiotic [5]. Briefly, colistin was discovered in 1949, it was introduced in Japan and in Europe during the 1950s and used in the United States in the form of colistimethate sodium in 1959 [6]. Unluckily, the use of colistin in intravenous formulations was abandoned in the early 1980s due to significant adverse effects as nephrotoxicity [7]. Currently, inhaled colistin has been successfully used for the treatment of pneumonia or chronic lung infection, also in cystic fibrosis patients with MDR Gramnegative bacteria and adverse events were not as frequent as previously reported [8,9]. At present, the reuse of intravenous colistin has been also reconsidered for the treatment of serious MDR $P$. aeruginosa, Acinetobacter baumannii and Enterobacteriaceae infections [10].

Many antimicrobial molecules have been discovered in the past, but not clinically implemented. For example, pyrrolomycins, a family of halogenated pyrrole antibiotics, produced by Actinosporangium vitaminophilum SF-2080, was isolated in 1983 [11]. A member of above mentioned family, pyrrolomycin $\mathrm{D}$, has a broad spectrum including Gram-positive, Gram-negative bacteria and fungi. In particular, it is strongly active against staphylococcal strains with minimum inhibitory concentrations (MICs) of $0.025 \mu \mathrm{g} / \mathrm{ml}$. Recently, we focused on pyrrolomycins C, D, F1, F2a, F2b, F3 and on some chemically synthesized derivatives, and we found that most of them show an important additional property that is an anti-staphylococcal biofilm activity. The use of antimicrobial agents active not only against planktonic microorganisms but also against biofilms, represents an important goal for an effective control of infections. In order to adequately assess the utility of these compounds, their toxicity against human cells was evaluated and some of them showed an interesting selective toxicity [12]. Another advantage of pyrrolomycins is related to the ability to obtain them, even if producing organisms are no longer available, by chemical synthesis. It is concluded that pyrrolomycins and their synthetic derivatives are potential compounds for developing novel effective chemical countermeasures against pathogens.

In conclusion, it is impossible imagine a modern medicine without the ability to control microbial diseases, there is an urgent clinical need

*Corresponding author: Domenico Schillaci, Department of Biological Chemical and Pharmaceutical Science and Technology, Università degli Studi di Palermo, Italy, Tel: +3909123891914; E-mail: domenico.schillaci@unipa.it

Received April 17, 2015; Accepted April 20, 2015; Published May 27, 2015

Citation: Schillaci D, Cascioferro S (2015) The Re-Discovering of Old Molecules to face the Antibiotic Crisis. J Microb Biochem Technol 7: e121. doi:10.4172/1948 5948.1000e121

Copyright: (c) 2015 Schillaci D, et al. This is an open-access article distributed under the terms of the Creative Commons Attribution License, which permits unrestricted use, distribution, and reproduction in any medium, provided the original author and source are credited 
Citation: Schillaci D, Cascioferro S (2015) The Re-Discovering of Old Molecules to face the Antibiotic Crisis. J Microb Biochem Technol 7: e121. doi:10.4172/1948-5948.1000e121

Page 2 of 2

of antibiotics and such emergence can be face revisiting old antibiotics by monitoring their toxicity with optimized dosing, and developing molecules as pyrrolomycins or others, extremely interesting in terms of activity, toxicity and additional characteristics like the ability to combat intrinsically form of resistance as biofilms.

\section{References}

1. Brown ED (2013) Is the GAIN Act a turning point in new antibiotic discovery? Can J Microbiol 59: 153-156.

2. Cascioferro S, Schillaci D (2014) The Future of Antibiotic: From the Magic Bullet to the Smart Bullet. J Microb Biochem Technol 6: 1-3.

3. Cascioferro S, Cusimano MG, Schillaci D (2014) Antiadhesion agents against Gram-positive pathogens. Future Microbiol 9: 1209-1220.

4. Cassir N, Rolain JM2, Brouqui P1 (2014) A new strategy to fight antimicrobial resistance: the revival of old antibiotics. Front Microbiol 5: 551.

5. Komura S, Kurahashi K (1979) Partial purification and properties of L-2,4diaminobutyric acid activating enzyme from a polymyxin $E$ producing organism. J Biochem 86: 1013-1021.

6. Reed MD, Stern RC, O'Riordan MA, Blumer JL (2001) The pharmacokinetics of colistin in patients with cystic fibrosis. J Clin Pharmacol 41: 645-654.

7. Biswas S, Brunel JM, Dubus JC, Reynaud-Gaubert M, Rolain JM (2012) Colistin: an update on the antibiotic of the 21st century. Expert Rev Anti Infect Ther 10: 917-934.
8. Lu Q, Luo R, Bodin L, Yang J, Zahr N, et al, (2012) Efficacy of high-dose nebulized colistin in ventilator-associated pneumonia caused by multidrugresistant Pseudomonas aeruginosa and Acinetobacter baumannii. Anesthesiology 117: 1335-1347.

9. Tumbarello M, De Pascale G, Trecarichi EM, De Martino S, Bello G, et al (2013) Effect of aerosolized colistin as adjunctive treatment on the outcomes of microbiologically documented ventilator-associated pneumonia caused by colistin-only susceptible gram-negative bacteria. Chest. 144: 1768-1775.

10. Falagas ME, Kasiakou SK (2005) Colistin: the revival of polymyxins for the management of multidrug-resistant gram-negative bacterial infections. Clin Infect Dis 40: 1333-1341.

11. Ezaki N, Koyama M, Shomura T, Tsuruoka T, Inouye S (1983) Pyrrolomycins $C, D$ and $E$, new members of pyrrolomycins. J Antibiot (Tokyo) 36: 1263-1267.

12. Schillaci D, Petruso S, Raimondi MV, Cusimano MG, Cascioferro S, et al. (2010) Pyrrolomycins as potential anti-staphylococcal biofilms agents. Biofouling 26 : 433-438.

13. http://www.cdc.gov/drugresistance/pdf/ar-threats-2013-508.pdf

14. http://www.washingtonpost.com/news/to-your-health/wp/2015/03/27/whitehouse-announces-plan-to-fight-antibiotic-resistant-bacteria/

15. http://www.bbc.com/news/health-28098838

16. https://www.whitehouse.gov/sites/default/files/docs/carb_national_strategy.pdf 